\title{
Frontiers of torenia research: innovative ornamental traits and study of ecological interaction networks through genetic engineering
}

\author{
Masahiro Nishihara', Takeshi Shimoda², Takashi Nakatsuka ${ }^{3}$ and Gen-ichiro Arimura ${ }^{4 *}$
}

\begin{abstract}
Advances in research in the past few years on the ornamental plant torenia (Torenia spps.) have made it notable as a model plant on the frontier of genetic engineering aimed at studying ornamental characteristics and pest control in horticultural ecosystems. The remarkable advantage of torenia over other ornamental plant species is the availability of an easy and high-efficiency transformation system for it. Unfortunately, most of the current torenia research is still not very widespread, because this species has not become prominent as an alternative to other successful model plants such as Arabidopsis, snapdragon and petunia. However, nowadays, a more global view using not only a few selected models but also several additional species are required for creating innovative ornamental traits and studying horticultural ecosystems. We therefore introduce and discuss recent research on torenia, the family Scrophulariaceae, for secondary metabolite bioengineering, in which global insights into horticulture, agriculture and ecology have been advanced. Floral traits, in torenia particularly floral color, have been extensively studied by manipulating the flavonoid biosynthetic pathways in flower organs. Plant aroma, including volatile terpenoids, has also been genetically modulated in order to understand the complicated nature of multi-trophic interactions that affect the behavior of predators and pollinators in the ecosystem. Torenia would accordingly be of great use for investigating both the variation in ornamental plants and the infochemical-mediated interactions with arthropods.
\end{abstract}

Keywords: Flavonoid, Flower color, Herbivore-induced plant volatiles (HIPVs), Indirect defense, Metabolic engineering, Torenia

\section{Introduction}

Torenia spps. are dicotyledonous plants that belong to the class Magnoliopsida, order Scrophulariales and family Scrophulariaceae, and include annuals and perennials. Torenia is the common name for several species in the genus Torenia (e.g. T. fournieri Lind., T. concolor Lind., T. asiatica L. and T. hybrida [T. fournieri x T. concolor]) [1]. In addition, $T$. fournieri and its hybrids, such as $T$. hybrida, are often called wishbone flowers or blue wings. Almost all species of torenia occur in tropical and subtropical Asia, Africa or Madagascar [2]. There are 50 species, 20 of which are from Cambodia, Laos and

\footnotetext{
* Correspondence: garimura@rs.tus.ac.jp

${ }^{4}$ Department of Biological Science \& Technology, Faculty of Industrial Science \& Technology, Tokyo University of Science, 6-3-1 Niijuku, Katsushika-ku, Tokyo 125-8585, Japan

Full list of author information is available at the end of the article
}

Vietnam, and 19 from Thailand [2]. Many hybrids have been produced in the last 30 years, with a variety of flower colors ranging from white with yellow throats to blue, cobalt, lavender and violet. However, torenia is not only a horticultural plant but also an experimental one with several useful characteristics. These include ease of genetic transformation, ability to differentiate adventitious shoots and roots, and capacity for in vitro flowering. Especially, a high-efficiency Agrobacteriummediated transformation system has been established in torenia, and this gives torenia a great advantage when conducting basic research using transgenic plants. The method can achieve a transformation rate of approximately 5\% [3]. The short generation time and small plant size of torenia make it possible to reduce the space and effort needed for maintenance compared with other ornamental model plant species such as the snapdragon

\section{() Bïomed Central}


and petunia. Torenia plants can be propagated vegetatively by stem cuttings, making it easy to obtain sufficient amounts of samples in a short time. Also useful is its small genome size of $171 \mathrm{Mb}$ [4], similar to that of Arabidopsis [5].

In addition, because torenia is a unique plant with a protruding embryo sac, it has been possible to establish an in vitro system for observing the guidance of pollen tubes using the naked embryo sac [6]. This feature has put torenia in the forefront of research on the fertilization process in higher plants in which torenia and Arabidopsis were used together for studies that, for instance, revealed the function of AtLURE1 peptides as pollen tube attractants [7]. In spite of these advantages, most torenia research is, unfortunately, not widespread over the world but rather remains restricted to a few research groups, mainly in Japan.

Flower color is one of the most noteworthy characteristics of ornamental plants, including torenia. Consequently, much effort has been devoted to understanding the molecular and biochemical mechanisms underlying pigment formation in flowers. Early research using transgenic plants indicated that the main pigments in torenia flowers consist of visible flavonoids, i.e., anthocyanins [8]. Torenia flowers also contain unpigmented or pale yellow flavonoids, flavones. This knowledge has allowed the successful modification of torenia flower color by genetic engineering. Torenia has thus joined the group of ornamental horticultural model plants in which flower color modification has been successfully achieved, such as Petunia hybrida (petunia), Dendranthema grandiflorum (chrysanthemum), Dianthus caryophyllus (carnation) and Rosa hybrida (rose) [9]. A particular advantage of using torenia as a model system is that it is related to the snapdragon, Antirrhinum majus, which has been a model plant in biochemical and developmental genetics for 80 years [10]. Since torenia is easy to transform and belongs to the same family (Scrophulariaceae) as snapdragon, torenia is an excellent platform for testing the function of genes isolated from torenia itself as well as those isolated from snapdragon.

Floral and foliar odors have been little investigated in torenia compared to the large amount of research on petunia and snapdragon. These two plants have been in the forefront of genetic and biotechnological applications, resource development (mutants, transcriptome datasets, genome and EST information) as well as floral studies [11-14]. We provided novel insight into the effects of foliage volatiles on ecological interactions between torenia plants and arthropods [15]. Indeed, such insights are critical for assessing the impact of metabolic engineering of volatiles on horticultural pest control, because volatiles affect the behavior of herbivores, carnivores, flower-visiting generalist predators and parasitoids (of the herbivores), and pollinators.

\section{Significance of the flavonoid biosynthetic pathway in torenia flowers}

Wild torenia species have flowers that range in color from blue to violet, and some of the species such as $T$. fournieri have a yellow splotch in the center. These colors are predominantly due to flavonoid pigments. The flavonoid biosynthesis pathway branches from the phenylpropanoid pathway leading to lignins and phytoalexins. Flavonoids are classified into several subclasses, such as flavones, flavonols, proanthocyanins, and anthocyanins [16]. Of these, anthocyanins and flavones in particular accumulate in torenia petals. For example, the blue petals of Torenia hybrida Summerwave blue contain mainly malvidin 3$O$ - $\beta$-D-glucoside-5-O-(6-O- $p$-coumaroyl)- $\beta$-D-glucoside together with minor anthocyanins, malvidin 3,5-diglucoside and peonidin derivatives (Figure 1) [17]. The violet petals of T. fournieri Crown violet accumulate five anthocyanins, delphinidin 3,5-O-diglucoside, cyanidin 3,5-O-diglucoside, petunidin 3,5-O-diglucoside, peonidin 3,5-O-diglucoside and malvidin 3,5-O-diglucoside (Figure 1) [8]. This cultivar contains, in addition, three major flavones, luteolin 7 glucoside, luteolin 7-glucuronide and apigenin 7-glucuronide. The flavonoid biosynthetic pathway has been well studied and the genes related to it have also been identified in petunia, snapdragon, Arabidopsis and maize [18]. Flavonoids also play extensive roles in various biological and environmental responses. In particular, they have a crucial role in plant-insect interactions [19].

The phenylpropanoid pathway, leading from phenylalanine to $p$-coumaroyl-CoA, is the entry point to downstream pathways including flavonoid biosynthesis. Structural genes required for flavonoid biosynthesis have been characterized in a variety of plant species, including torenia, as mentioned above. Transcriptional regulation of flavonoid biosynthesis is a particularly active research topic, and notably shows combinatorial regulation by the MYB/bHLH/WDR $(\mathrm{MBW})$ transcriptional complex in a suite of plant species $[20,21]$. Such a tripartite MBW complex was found to regulate anthocyanin biosynthesis in petunia flowers [22] and grapes [23], and proanthocyanidin (PA) accumulation in Arabidopsis seed coats [24]. Moreover, ANTHOCYANIN2 (AN2), a well-defined MYB-type transcription factor that is a major determinant of flower color variation in petunia, has important effects on pollinator preference. Variation in AN2 homologues may also account for flower color variation in more distantly related taxa, such as snapdragon [25], suggesting that variation in highly specific transcription factors may be a major source of natural phenotypic variation and perhaps the favored target of natural selection in other species as well [26]. This is in line with the significance of gene duplication of anthocyaninregulating MYB transcription factors as a genetic basis of the flower color diversification found in the Mimulus genus, which contains five species native to central Chile 

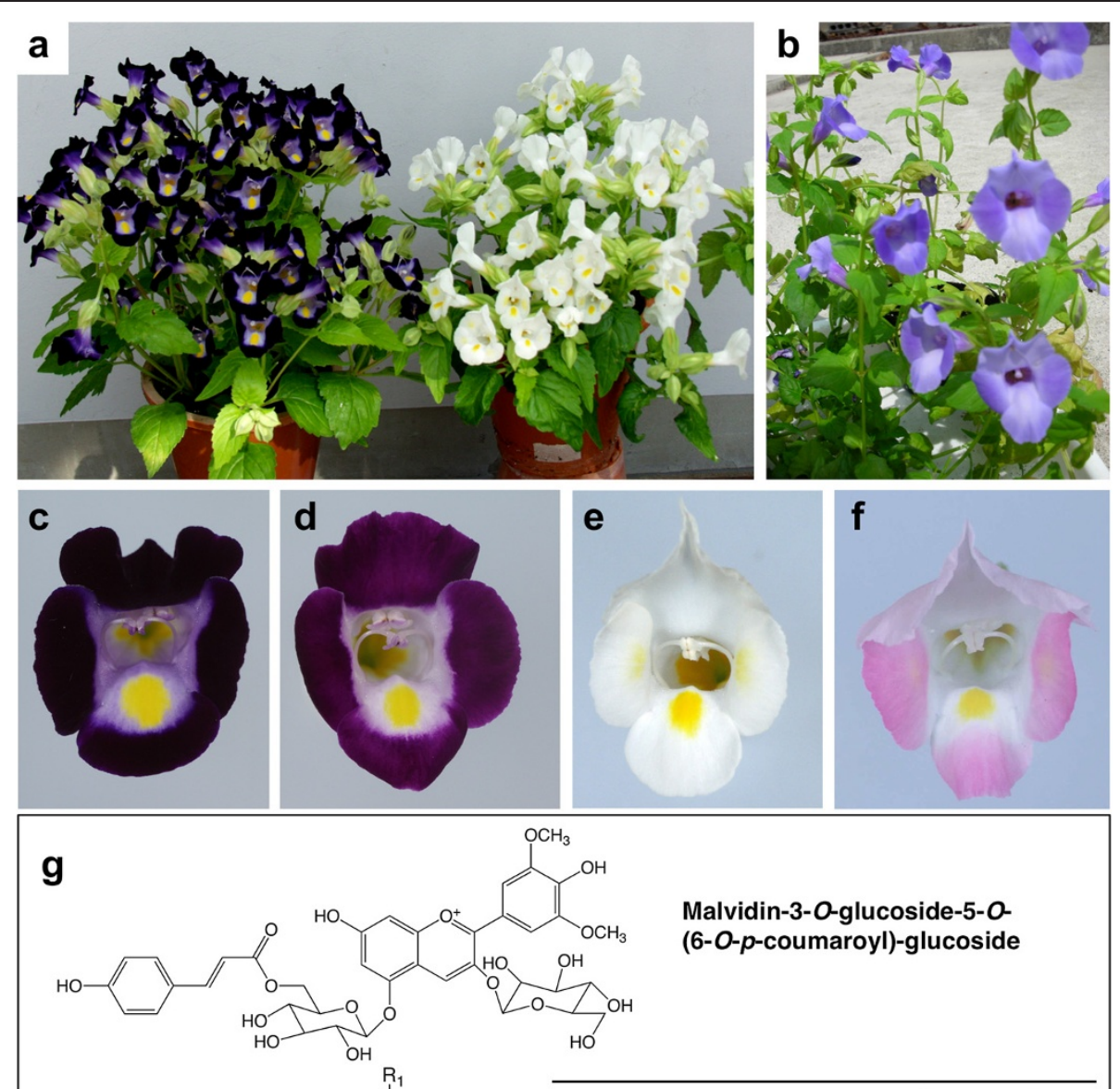

Malvidin-3-O-glucoside-5- $O$ (6-O-p-coumaroyl)-glucoside

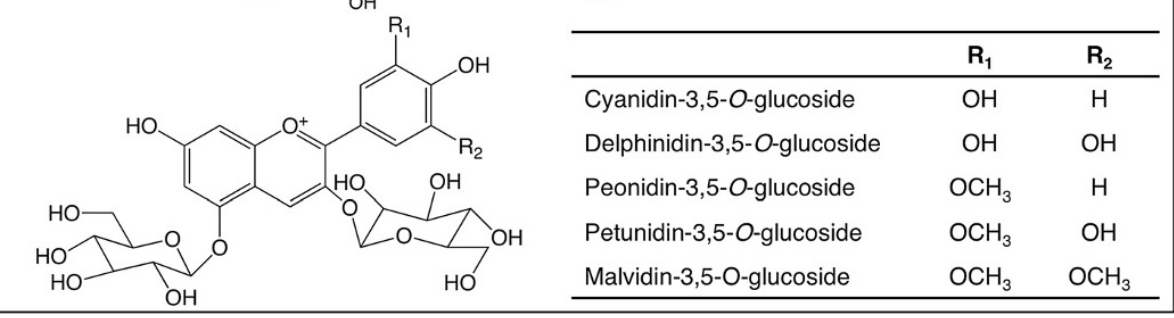

Figure 1 Genetic engineering of torenia flower color. Various species of torenia used for transformation: Torenia fournieri cv. Crown violet (Left in a)), Crown white (Right in a)) and T. hybrida b). c) Flower of Crown violet. d) Transgenic flower of Crown violet with reduced flavone derivatives. e) Flower of Crown white. f) Transgenic flower of Crown white that accumulated pelargonidin derivatives. g) Representation of torenia floral anthocyanins.

[27]. More recently, it was reported that the genes TfMYB1 and $T f b H L H 1$ are expressed in torenia flowers and involved in anthocyanin biosynthesis [28].

The genera of Scrophulariaceae are mainly insect pollinated. For instance, T. fournieri is known to be mainly pollinated by stingless bees in Thailand, and potentially by hummingbirds in North America [1]. Each class of pollinator exhibits a particular color preference. Bees typically tend to prefer blue, purple and mauve flowers, whereas butterflies choose pink and red flowers [29]. The flowers of T. fournieri exhibit most of these flower colors, and bumblebees, attracted by the floral characteristics, play a role in the pollination [30]. Bee vision is trichromatic but more sensitive to short wave length light than human vision. Bees, therefore, can see not only colors created by anthocyanins visible to humans but also those in the ultra-violet range that humans cannot see. This means that bees can detect nectar guides, which are ultra-violet absorbing zones on petals that attract particular pollinators [31]. Nectar guides contain, in particular, flavonols and flavones which have intense spectral absorption in the 340-380 nanometer region [31]. Flavones are likely to act as copigments, because considerable amounts of flavone derivatives accumulate in torenia petals and a loss of dihydroflavonol 4-reductase (DFR) function in torenia causes flavone accumulation, making the transgenic flowers bluer [8,32]. However, the yellow splotch of torenia flowers is a prominent mark and 
may function specifically to guide the most effective pollinators to the pollen. Yellow pigmentation is attributed to carotenoids in several torenia cultivars (Crown violet, Lemon drop, and Suzie wong), and carotenogenic genes are responsible for the carotenoid biosynthesis that coordinates petal carotenoid variegation (pers. comm. Dr. Sanae Kishimoto, National Institute of Floricultural Science, Japan).

Modulation of torenia floral traits by genetic engineering A simple and efficient transformation system has been established in torenia and therefore various transformation studies have targeted ornamental characteristics in this plant during the past 15 years [5]. These studies have produced useful phenotypic modifications for ornamental traits in flowers such as color, pattern, shape, size, and longevity. In ornamental plants, including torenia, genetic transformations have been applied for producing novel flower colors mainly by metabolic engineering of the flavonoid biosynthetic pathway [33,34].

Application of transgenic techniques to torenia has produced a diversity of flower colors, including white, yellow, pink and red instead of the original violet or blue color in cultivars of T. fournieri or T. hybrida (Table 1). The genes for flavonoid biosynthesis (e.g., chalcone synthase $(C H S)$ and $D F R)$ were manipulated to reduce flower pigmentation by down-regulation of these genes with cosuppression or antisense strategies [8,17,35,36] and, more recently, by RNA interference (RNAi) technology $[37,38]$. Similarly, overexpression and/or downregulation of a suite of genes involved in the flavonoid biosynthetic pathway resulted in variation of flower colors in torenia $[32,39,40]$. In addition to these classical strategies, a recent innovation has been to divert the metabolic flux towards non-native pigments (e.g., aurone). The coexpression of chalcone 4'-glucosyltransferase $\left(A m 4^{\prime} C G T\right)$ and aureusidin synthase $(A m A S 1)$ genes, responsible for the biosynthesis of the yellow aurone pigment in snapdragon, and knockdown of a toreniaflavanone 3-hydroxylase gene $(F 3 H)$ or $D F R$ successfully produced aureusidin 6-O-glucoside and thus yellow flowers [41].

Chimeric REpressor gene-Silencing Technology (CRES$\mathrm{T}$; [42] has notably been applied to torenia and other floricultural plants such as chrysanthemum, gentian, cyclamen, lisianthus, and morning glory $[43,44]$. In this system,

Table 1 Summary of flower color modification of torenia plants by genetic engineering

\begin{tabular}{|c|c|c|c|c|}
\hline Target material & Gene and method & Gene origin & Flower phenotype & Reference \\
\hline \multicolumn{5}{|l|}{ Torenia fournieri } \\
\hline cv. Crown violet & Sense CHS or DFR, antisense CHS or DFR & Torenia & White to pale blue & {$[8,35,36]$} \\
\hline cv. Crown reddish-purple & Sense CHS or DFR, antisense CHS or DFR & Torenia & Wavy-patterned & {$[8,35,36]$} \\
\hline cv. Common violet & Sense CHS or DFR, antisense CHS or DFR & Torenia & Wavy-patterned & {$[8,35,36]$} \\
\hline cv. Crown violet & GPT-RNAi & Torenia & Lighter colored & [39] \\
\hline cv. Crown violet & DEF-SRDX & Torenia & Partially decolorized & {$[50]$} \\
\hline cv. Crown violet & Transcription factors-SRDX & Arabidopsis & Various color patterns & {$[43,44,48]$} \\
\hline cv. Crown violet & MYB24-SRDX & Arabidopsis & Lacked color at both sides of the petal & {$[47]$} \\
\hline cv. Crown violet & TCP3-SRDX & Arabidopsis & Various color patterns & [46] \\
\hline \multicolumn{5}{|l|}{$\begin{array}{l}\text { T. hybrida } \\
(T \text {. fournieri } \times T \text {. concolor) }\end{array}$} \\
\hline cv. Summerwave blue & Sense $C H S$, sense $D F R$ & Torenia & White to pale blue & {$[17]$} \\
\hline Inbred line T-33 & Sense CHS or DFR, sense $F 3^{\prime} 5^{\prime} H$ & Torenia & Yellow, pink & {$[17]$} \\
\hline cv. Summerwave blue & Sense $F 3^{\prime} H$, sense $F 3^{\prime} 5^{\prime} H$ & Torenia & Reddish & [32] \\
\hline cv. Summerwave blue & Sense FNSII & Torenia & Pale blue & [32] \\
\hline cv. Summerwave blue & CHS-RNAi & Torenia & White to pale blue & {$[37]$} \\
\hline \multirow[t]{2}{*}{ cv. Summerwave blue } & Sense $A S 1$ and sense $4^{\prime} C G T$ & Snapdragon & Yellow & [41] \\
\hline & F3H-RNAi, DFR-RNAi & Torenia & & \\
\hline cv. Summerwave blue & Sense or antisense ANS, ANS-RNAi & Torenia & White to pale blue & {$[38]$} \\
\hline \multirow[t]{2}{*}{ cv. Summerwave blue } & $F 3^{\prime} H-R N A i, F 3^{\prime} 5^{\prime} H-R N A i$ & Torenia & Pink & {$[40]$} \\
\hline & Sense DFR & Rose or pelargonium & & \\
\hline \multirow[t]{2}{*}{ cv. Summerwave violet } & $F 3^{\prime} H-R N A i, F 3^{\prime} 5^{\prime} H-R N A i$ & Torenia & Darker pink & {$[40]$} \\
\hline & Sense DFR & Rose or pelargonium & & \\
\hline
\end{tabular}

Abbreviations: ANS anthocyanidin synthase, AS aureusidin synthase, 4'CGT chalcone 4-O-glucosyltransferase, CHS chalcone synthase, DEF DEFICIENS, DFR dihydroflavonol 4-reductase, $F 3 H$ flavanone 3-hydroxylase, $F 3^{\prime} H$ flavonoid 3'-hydroxylase, F3'5'H flavonoid 3',5'- hydroxylase, FNSII flavone synthase II, GLO GLOBOSA, GPT glucose 6-phosphate/phosphate translocator, TCP TEOSINTE BRANCHED1/CYCLOIDEA/PROLIFERATING CELL FACTORS 1/2. 
intriguingly, the transcription factor is able to switch from being an activator to being a repressor by fusion to the EAR motif (SRDX), consisting of only 12 amino acids originally derived from SUPERMAN, which acts as strong repressor [45]. Because chimeric repressors can suppress expression of the target genes even in the face of active endogenous transcription factors, transgenic plants expressing the chimeric repressors produce phenotypes similar to those from loss-of-function mutants in the CRES-T system. In general, efficient suppression of redundantly expressed genes and genes in different plant species is rarely achieved by genetic engineering. However, the CRES-T system, an efficient gene suppression system, offers a powerful tool for this purpose. For example, distinctive color patterns in torenia and Chrysanthemum morifolium flowers have been created as a result of reduced anthocyanin accumulation caused by the expression of the repressor of Arabidopsis TCP3 transcription factor [46]. Petals inside the flower buds also exhibited a distinct color pattern in transgenic torenia plants as a consequence of overexpression of the Arabidopsis MYB24 repressor with a transcriptional repression domain (MYB24$S R D X)$ [47]. Of interest is that transgenic torenia plants with variously modified traits have been produced by the collective transformation of about 50 transcription factors using CRES-T [48]. Moreover, morphological change in the shapes and sizes of flowers or leaves has been achieved by the overexpression of chimeric repressors of the B- and C-class homeotic genes. AGAMOUS (AG) terminates the floral meristem and promotes the development of stamens and carpels in Arabidopsis, but transgenic torenia plants expressing AG-SRDX showed pleiotropic changes such as serration in petal margins, anthocyanin accumulation and morphological change in the stigma surface, and formation of extra vascular bundles in petals and styles [49]. Up or down-regulation of these orthologue genes in torenia, $T f G L O$ and TfDEF, also resulted in various interesting phenotypes such as purple-stained sepals, or serrated petals and partially decolorized petals [50].

Finally, it should be taken into account that, in addition to genetic engineering based on gene delivery, pigment mutations are also produced in torenia by heavy ion beam irradiation [51-53]. Moreover, mutations of petal color are also caused by gamma irradiation [54]. These findings suggest that combining transgenic strategies and radiation breeding would greatly facilitate changes in several flower traits. For instance, the torenia mutant (no. 252), generated by ion-beam irradiation of a transgenic torenia with modified flower color, formed flower buds but did not open flowers, whereas wild-type torenia plants usually open flowers until flower buds have developed at the upper joint [55]. This mutant exhibited a missense mutation in the coding region of the UFO (UNUSUAL FLORAL ORGANS) gene that induced a sepaloid phenotype in which the second whorls were changed to sepal-like organs [55].

Insertional mutagenesis provides a powerful tool for studying gene functions by the forward genetic approach, and especially retrotransposons have several advantages over traditional DNA-type insertion elements (Kumar and Hirochika 2001). It is also likely that transposon-tagging in torenia may be possible, as we have recently identified a retrotransposon in genes required for anthocyanin synthesis (Nishihara et al., unpublished). Similar approaches have been used successfully in Lotus japonicus [56] and rice [57,58] using the LORE1 and Tos17 transposons, respectively. Moreover, a DNA-type transposon (Ttft1) that belongs to the $\mathrm{En} / \mathrm{Spm}$ superfamily has been identified in EMS-induced torenia mutants (Nishijima et al., 2013) and this element might be also useful for transposon tagging in torenia. There has been little thorough investigation, however, of other transient assay systems, such as agroinfiltration, biolistics and virus-induced-gene-silencing (VIGS), that are of use in other plant species. However, novel methods for transient foreign-gene introduction into torenia cells have been developed using ArF excimer laser-induced shock waves [59].

\section{Modulation of defense properties in torenia by genetic engineering}

Plants produce a diversity of volatile compounds from their flowers, leaves and other organs. These compounds include terpenoids, phenylpropanoids/benzenoids, fatty acid derivatives and amino acid derivatives. These compounds play a number of roles in the interaction of plants with the environment $[60,61]$. Floral volatiles are well known to attract pollinators and can also function as repellants against herbivores or as phytoalexins against plant pathogens [62]. Also of interest is that leaf volatiles emitted from plants damaged by herbivorous arthropods (HIPVs: Herbivore-induce plant volatiles), attract natural enemies of the herbivores [63]. These volatiles therefore function as indirect plant defenses against herbivores. HIPVs also induce or prime defense responses against future herbivore attack in neighboring plants $[64,65]$, influence the behavior of insect herbivores or pollinators [66], and interfere with infection by plant pathogens [66].

Torenia is frequently susceptible to thrips, aphids and mites [1]. Moreover, the accelerated reproductive rate allows these pest populations to adapt quickly to resist pesticides, so chemical control methods can become somewhat ineffectual when the same pesticide is used over a prolonged period. Accordingly, semiochemicalbased pest management methods are being developed for ornamental plants with plant volatile-based attractants/repellents that may be used as synthetic chemicals or products of genetic engineering. However, little is known about the characteristics of torenia in ecological 
interaction networks. To correctly assess the impact of genetically engineered alterations of plant odor in horticultural pest control, it is essential to understand the complicated nature of arthropod attraction mediated by volatile blends. For example, natural enemies of pest herbivores may tend not to respond strongly to novel HIPV blends from transgenic plants at the flowering stage so as to protect themselves against intraguild predation by flower-visiting generalist predators. To evaluate carnivore responses to HIPV blends and to floral volatiles, the ability of transgenic T. hybrida plants to attract predatory mites (Phytoseiulus persimilis) has recently been studied [15]. The transgenic plants, when infested with two-spotted spider mites (Tetranychus urticae), emitted a blend of HIPVs comprising a monoterpene (linalool), a homoterpene [(E)-4,8-dimethyl-1,3,7-nonatriene] and sesquiterpenes ( $\alpha$-zingiberene, $\alpha$-bergamotene, $\gamma$ curcumene and unidentified sesquiterpene), as well as a trans-volatile [(E)- $\beta$-ocimene] (Figure 2) [15]. The transvolatile enhanced the attraction of $P$. persimilis when added to an HIPV blend from the infested transgenic plants. However, floral volatiles, comprising 3-ethyl4-methylpentanol and a suite of monoterpenes [(+)-2carene, $\alpha$-terpinene, $p$-cymene and limonene], abolished the supporting effect of the trans-volatile embedded in the natural HIPVs. Transgenic torenia thus provides an intriguing tritrophic system, as predator attraction was enhanced only when non-flowering plants were infested (Figure 2) [15]. The attractiveness of a specific volatile compound thus markedly depends on the background odors, including both HIPVs and floral volatiles. Because of such complexity, it is necessary to construct model systems using torenia and other plant species in order to clarify the ecological and horticultural significance of HIPVs.

Metabolic engineering of torenia also demonstrated the abilities of plants to resist fungi and arthropod herbivores. T. hybrida manipulated to produce Arabidopsis agmatine coumaroyltransferase (AtACT), which is involved in phytoalexin biosynthesis, was resistant to a necrotrophic fungus, Botrytis cinerea, unlike the wild-type progenitors [67]. Collectively, transgenic torenia plants have proven to be an ideal platform for a wide array of pest controls according to the results of various gene manipulations.

\section{Concluding remarks}

In summary, recent advances in torenia research have made this ornamental plant notable for genetic engineering aimed at studying both flower characteristics [5] and pest control [15]. Torenia plants with manipulated flower colors and aroma could be used to investigate interactions between plants and pollinators or floral herbivores. Horticultural ecosystems are, however, very complicated and

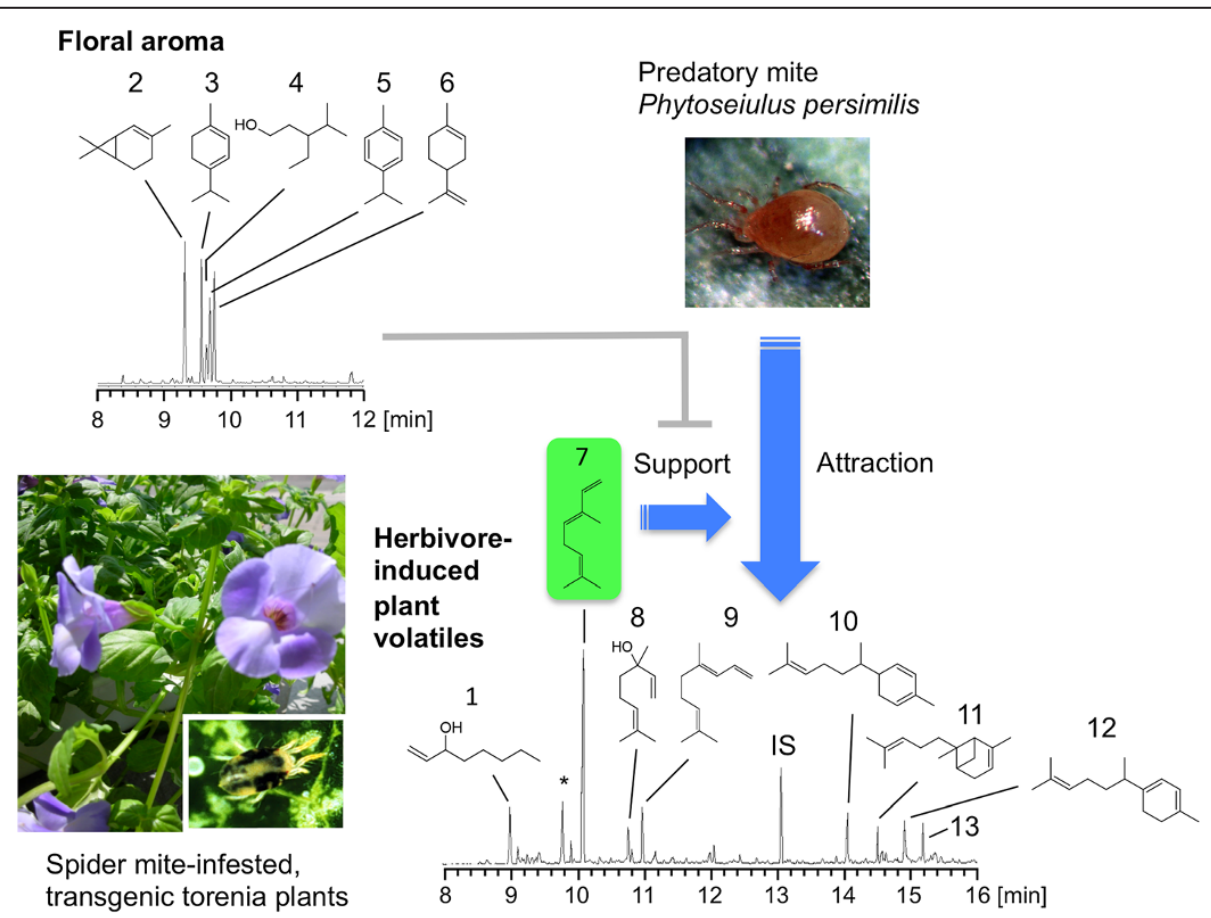

Figure 2 Tritrophic interaction network in torenia Summerwave blue (T. hybrida) for the predatory mite-associated indirect defense responses to spider mites. Arrows and bars indicate positive and negative interactions, respectively. 1. 1-octen-3-ol; 2. (+)-2-carene; 3. aterpinene; 4. 3-ethyl-4-methylpentanol; 5. p-cymene; 6. limonene; 7. (E)- $\beta$-ocimene; 8. linalool; 9. (E)-4,8-dimethyl-1,3,7-nonatriene; 10. azingiberene; 11. a-bergamotene; 12. $\gamma$-curcumene; 13. unidentified sesquiterpene; IS, internal standard. An asterisk (*) in volatile profiles indicates air contamination. 
flexible. For instance, natural enemies of foliage herbivores (folivores) may occasionally be unresponsive to HIPV cues from ornamental plants at flowering stages, so as to protect themselves against intraguild predation by flower-visiting generalist predators. Moreover, damage by folivores can result in delayed and shortened flowering periods and smaller and fewer open flowers. This reduces the floral rewards, such as nectar and pollen, exploited by flower visitors (reviewed in [68]). This is the end result of trade-off between defense and reproduction in plants. Therefore, a wide range of systematic studies using torenia in addition to other plant systems should be conducted to understand realistic horticultural ecosystems, where huge numbers of plants, animals, and microorganisms interact and achieve coevolution and biodiversity.

\section{Abbreviations \\ CHS: Chalcone synthase; CRES-T: Chimeric REpressor gene-silencing technology; DFR: Dihydroflavonol 4-reductase; HIPVs: Herbivore-induced plant volatiles; RNAi: RNA interference; VIGS: Virus-induced-gene-silencing.}

\section{Competing interests}

The authors declare no competing interests.

\section{Authors' contributions}

MN and GA conceived the study and drafted the early version of the manuscript. TS and TN commented on the manuscript, revised the text and structure, and outlined it several times together with MN and GA. All authors read and approved the final manuscript.

\section{Authors' information}

MN's research focuses on the elucidation of the molecular mechanisms that control flower pigmentation and genetic engineering of novel colored flowers. TS is currently working on behavioral responses of pest herbivores and their natural enemies to herbivore-induced plant volatiles. TN's research interest is focused on molecular breeding of ornamental flowers. His research interests include plant secondary metabolism, floral morphology and molecular engineering. GA's research focuses on molecular ecology of plant-insect interactions mediated via volatiles. He has intensively studied mechanisms of resistance to arthropod herbivores.

\section{Acknowledgements}

We gratefully acknowledge Drs. Yoshikazu Tanaka (Suntory Ltd., Japan) and Ryutaro Aida and Norihiro Ohtsubo (National Institute of Floricultural Science, Japan) for providing the torenia materials and literature information. This work was financially supported in part by Grants-in-Aid for Scientific Research from the Japan Society for the Promotion of Science to GA (No. 24770019), TS (Nos. 22380038 and 23510271) and MN (Nos. 21658013 and 25660030), by Global COE Program A06 of Kyoto University, and by MEXT Grants for Excellent Graduate Schools.

\section{Author details}

'Iwate Biotechnology Research Center, Kitakami, Iwate 024-0003, Japan. ${ }^{2}$ National Agricultural Research Center, Tsukuba, Ibaraki 305-8666, Japan. ${ }^{3}$ Department of Biological and Environmental Science, Graduate School of Agriculture, Shizuoka University, Shizuoka 422-8529, Japan. ${ }^{4}$ Department of Biological Science \& Technology, Faculty of Industrial Science \& Technology, Tokyo University of Science, 6-3-1 Niijuku, Katsushika-ku, Tokyo 125-8585, Japan.

Received: 10 May 2013 Accepted: 21 June 2013

Published: 26 June 2013

\section{References}

1. Office of the Gene Technology Regulator, Department of Health and Ageing, Australian Govermnment: The biology ofTorenia spp. (torenia); 2008.
2. Yamazaki T: A revision of the genera Limnophila and Torenia from Indochina. J Fac Sci Univ Tokyo (III) 1985, 13:575-625.

3. Aida R: A protocol for transformation of Torenia. Methods Mol Biol 2012, $847: 267-274$

4. Kikuchi S, Tanaka H, Shiba T, Mii M, Tsujimoto H: Genome size, karyotype, meiosis and a novel extra chromosome in Torenia fournieri, T. baillonii and their hybrid. Chromosome Res 2006, 14:665-672.

5. Aida R: Torenia fournieri (torenia) as a model plant for transgenic studies. Plant Biotechnol 2008, 25:541-545.

6. Higashiyama T, Kuroiwa H, Kawano S, Kuroiwa T: Guidance in vitro of the pollen tube to the naked embryo sac of Torenia fournieri. Plant Cell 1998, 10:2019-2032

7. Takeuchi H, Higashiyama T: A species-specific cluster of defensin-like genes encodes diffusible pollen tube attractants in Arabidopsis. PLoS Biol 2012, 10:e1001449

8. Aida R, Yoshida K, Kondo T, Kishimoto S, Shibata M: Copigmentation gives bluer flowers on transgenic torenia plants with the antisense dihydroflavonol-4-reductase gene. Plant Sci 2000, 160:49-56.

9. Chandler SF, Sanchez C: Genetic modification; the development of transgenic ornamental plant varieties. Plant Biotechnol J 2012, 10:891-903.

10. Schwarz-Sommer Z, Davies B, Hudson A: An everlasting pioneer: the story of Antirrhinum research. Nat Rev Genet 2003, 4:657-666.

11. Klahre U, Gurba A, Hermann K, Saxenhofer M, Bossolini E, Guerin PM, Kuhlemeier C: Pollinator choice in Petunia depends on two major genetic Loci for floral scent production. Curr Biol 2011, 21:730-739.

12. VAn Moerkercke A, Haring MA, Schuurink RC: The transcription factor EMISSION OF BENZENOIDS II activates the MYB ODORANT1 promoter at a MYB binding site specific for fragrant petunias. Plant $J$ 2011, 67:917-928.

13. Colquhoun TA, Clark DG: Unraveling the regulation of floral fragrance biosynthesis. Plant Sig Behav 2011, 6:378-381.

14. Wright GA, Lutmerding A, Dudareva N, Smith BH: Intensity and the ratios of compounds in the scent of snapdragon flowers affect scent discrimination by honeybees (Apis mellifera). J Comp Physiol A 2005, 191:105-114.

15. Shimoda T, Nishihara M, Ozawa R, Takabayashi J, Arimura G: The effect of genetically enriched $(E)$ - $\beta$-ocimene and the role of floral scent in the attraction of the predatory mite Phytoseiulus persimilis to spider mite-induced volatile blends of torenia. New Phytol 2012, 193:1009-1021

16. Grotewold E: The science of flavonoids. London: Springer-Verlag; 2006.

17. Suzuki K, Xue H, Tanaka Y, Fukui Y, Fukuchi-Mizutani M, Murakami Y, Katsumoto Y, Tsuda S, Kusumi T: Flower color modifications of Torenia hybrida bycosuppression of anthocyanin biosynthesis genes. Mol Breed 2000, 6:239-246.

18. Grotewold E: The genetics and biochemistry of floral pigments Ann Rev Plant Biol 2006, 57:761-780.

19. Simmonds MS: Flavonoid-insect interactions: recent advances in our knowledge. Phytochemistry 2003, 64:21-30.

20. Feller A, Machemer K, Braun EL, Grotewold E: Evolutionary and comparative analysis of MYB and bHLH plant transcription factors. Plant J 2011, 66:94-116.

21. Hichri I, Barrieu F, Bogs J, Kappel C, Delrot S, Lauvergeat V: Recent advances in the transcriptional regulation of the flavonoid biosynthetic pathway. J Exp Bot 2011, 62:2465-2483.

22. Quattrocchio F, Verweij W, Kroon A, Spelt C, Mol J, Koes R: PH4 of Petunia is an R2R3 MYB protein that activates vacuolar acidification through interactions with basic-helix-loop-helix transcription factors of the anthocyanin pathway. Plant Cell 2006, 18:1274-1291.

23. Matus JT, Poupin MJ, Canon P, Bordeu E, Alcalde JA, Arce-Johnson P: Isolation of WDR and bHLH genes related to flavonoid synthesis in grapevine (Vitis vinifera L.). Plant Mol Biol 2010, 72:607-620.

24. Gonzalez A, Zhao M, Leavitt JM, Lloyd AM: Regulation of the anthocyanin biosynthetic pathway by the $\pi \mathrm{G} 1 / \mathrm{bHLH} / \mathrm{Myb}$ transcriptional complex in Arabidopsis seedlings. Plant J 2008, 53:814-827.

25. Schwinn K, Venail J, Shang Y, Mackay S, Alm V, Butelli E, Oyama R, Bailey P, Davies K, Martin C: A small family of MYB-regulatory genes controls floral pigmentation intensity and patterning in the genus Antirrhinum. Plant Cell 2006, 18:831-851.

26. Hoballah ME, Gübitz T, Stuurman J, Broger L, Barone M, Mandel T, Dell'Olivo A, Arnold M, Kuhlemeier C: Single gene-mediated shift in pollinator attraction in Petunia. Plant Cell 2007, 19:779-790. 
27. Cooley AM, Modliszewski JL, Rommel ML, Willis JH: Gene duplication in Mimulus underlies parallel floral evolution via independent trans-regulatory changes. Curr Biol 2011, 21:700-704.

28. Nishijima T, Morita Y, Sasaki K, Nakayama M, Yamaguchi H, Ohtsubo N, Niki T, Niki T: A torenia (Torenia fournieri Lind. ex Fourn.) novel mutant 'flecked' produces variegated flowers by insertion of a DNA transposon into an R2R3-MYB gene. J Japan Soc Hort Sci 2013, 82:39-50.

29. Kevan PG, Baker HG: Insects as flower visitors and pollinators. Annu Rev Entomol 1983, 28:407-453.

30. Armstrong JE: Lever action anthers and the forcible shedding of pollen in Torenia (Scrophulariaceae). Am J Bot 1992, 79:34-40.

31. Thompson WR, Meinwald J, Aneshansley D, Eisner T: Flavonols: pigments responsible for ultraviolet absorption in nectar guide of flower. Science 1972, 177:528-530

32. Ueyama Y, Suzuki K, Fukuchi-Mizutani M, Fukui Y, Miyazaki K, Ohkawa H, Kusumi T, Tanaka Y: Molecular and biochemical characterization of torenia flavonoid 3'-hydroxylase and flavone synthase II and modification of flower color by modulating the expression of these genes. Plant Sci 2002, 163:253-263.

33. Nishihara M, Nakatsuka T: Genetic engineering of flavonoid pigments to modify flower color in floricultural plants. Biotechnol Lett 2011 33:433-441.

34. Tanaka Y, Brugliera F, Kalc G, Senior M, Dyson B, Nakamura N, Katsumoto Y Chandler S: Flower color modification by engineering of the flavonoid biosynthetic pathway: practical perspectives. Biosci Biotechnol Biochem 2010, 74:1760-1769.

35. Aida R, Kishimoto S, Tanaka Y, Shibata M: Modification of flower color in torenia (Torenia fournieri Lind.) by genetic transformation. Plant Sci 2000 153:33-42.

36. Aida R, Shibata M: Transgenic Torenia fournieri Lind. (torenia). Biotechnology in Agriculture and Forestry. Transgenic Crops III 2001, 48:294-305.

37. Fukusaki E, Kawasaki K, Kajiyama S, An Cl, Suzuki K, Tanaka Y, Kobayashi A: Flower color modulations of Torenia hybrida by downregulation of chalcone synthase genes with RNA interference. J Biotechnol 2004, 111:229-240.

38. Nakamura N, Fukuchi-Mizutani M, Miyazaki K, Suzuki K, Tanaka Y: RNAi suppression of the anthocyanidinsynthase gene in Torenia hybrida yields white flowers with higher frequency and better stability than antisense and sense suppression. Plant Biotechnol 2006, 23:13-18.

39. Nagira Y, Shimamura K, Hirai S, Shimanuki M, Kodama H, Ozeki Y: Identification and characterization of genes induced for anthocyanin synthesis and chlorophyll degradation in regenerated torenia shoots using suppression subtractive hybridization, CDNA microarrays, and RNA techniques. J Plant Res 2006, 119:217-230.

40. Nakamura N, Fukuchi-Mizutani M, Fukui Y, Ishiguro K, Suzuki K, Suzuki H, Okazaki K, Shibata DYT: Generation of pink flower varieties from blue Torenia hybrida by redirecting the flavonoid biosynthetic pathway from delphinidin to pelargonidin. Plant Biotechnol 2010, 27:375-383.

41. Ono E, Fukuchi-Mizutani M, Nakamura N, Fukui Y, Yonekura-Sakakibara K, Yamaguchi M, Nakayama T, Tanaka T, Kusumi T, Tanaka Y: Yellow flowers generated by expression of the aurone biosynthetic pathway. Proc Natl Acad Sci USA 2006, 103:11075-11080.

42. Hiratsu K, Matsui K, Koyama T, Ohme-Takagi M: Dominant repression of target genes by chimeric repressors that include the EAR motif, a repression domain, in Arabidopsis. Plant J 2003, 34:733-739.

43. Mitsuda N, Takiguchi Y, Shikata M, Sage-Ono K, Ono M, Sasaki K, Yamaguchi $H$, Narumi T, Tanaka T, Sugiyama M, et al: The new FioreDB database provides comprehensive information on plant transcription factors and phenotypes induced by CRES-T in ornamental and model plants. Plant Biotechnol 2011, 28:123-130.

44. Mitsuda N, Umemura Y, Ikeda M, Shikata M, Koyama T, Matsui K, Narumi T, Aida R, Sasaki K, Hiyama T, et al: FioreDB: a database of phenotypic information induced by the chimeric repressor silencing technology (CRES-T) in Arabidopsis and floricultural plants. Plant Biotechnol 2008, 25:37-43.

45. Hiratsu K, Ohta M, Matsui K, Ohme-Takagi M: The SUPERMAN protein is an active repressor whose carboxy-terminal repression domain is required for the development of normal flowers. FEBS Lett 2002, 514:351-354.

46. Narumi T, Aida R, Koyama T, Yamaguchi H, Sasaki K, Shikata M, Nakayama M, Ohme-Takagi M, Ohtsubo N: Arabidopsis chimeric TCP3 repressor produces novel floral traits in Torenia fournieri and Chrysanthemum morifolium. Plant Biotechnol 2011, 28:131-140.

47. Sasaki K, Yamaguchi H, Narumi T, Shikata M, Oshima Y, Nakata M, Mitsuda N Ohme-Takagi M, Ohtsubo N: Utilization of a floral organ-expressing AP1 promoter for generation of new floral traits in Torenia fournieri Lind. Plant Biotechnol 2011, 28:181-188.

48. Shikata M, Narumi T, Yamaguchi H, Sasaki K, Aida R, Oshima Y, Takiguchi Y, Ohme-Takagi M, Mitsuda N, Ohtsubo N: Efficient production of novel floral traits in torenia by collective transformation with chimeric repressors of Arabidopsis transcription factors. Plant Biotechnol 2011, 28:189-199.

49. Narumi T, Aida R, Niki T, Nishijima T, Mitsuda N, Hiratsu K, Ohme-Takagi M, Ohtsubo N: Chimeric AGAMOUS repressor induces serrated petal phenotype in Torenia fournieri similar to that induced by cytokinin application. Plant Biotechnol 2008, 25:45-53.

50. Sasaki K, Aida R, Yamaguchi H, Shikata M, Niki T, Nishijima T, Ohtsubo N: Functional divergence within class B MADS-box genes TfGLO and TfDEF in Torenia fournieri Lind. Mol Genet Genomics 2010, 284:399-414.

51. Miyazaki K, Suzuki K, Iwaki K, Kusumi T, Abe T, Yoshida S, Fukui H: Flower pigment mutations induced by heavy ion beam irradiation in an interspecific hybrid of Torenia. Plant Biotechnol 2006, 23:163-167.

52. Sasaki K, Aida R, Niki T, Yamaguchi H, Narumi T, Nishijima T, Hayashi $Y$, Ryuto H, Fukunishi N, Abe T, Ohtsubo N: High-efficiency improvement of transgenic torenia flowers by ion beam irradiation. Plant Biotechnol 2008 25:81-89.

53. Ohtsubo N, Sasaki K, Aida R, Ryuto H, Ichida H, Hayashi $Y$, Abe T: Efficient modification of floral traits by heavy-ion beam irradiation on transgenic Torenia. Meth Mol Biol 2012, 847:275-289.

54. Suwanseree WW, Teerakathiti T, Wongchaochant S, Taychasinpitak T: Petal color and petal form mutations observed in Torenia hybrida following gamma irradiation in vitro. Kasetsart J (Nat Sci) 2011, 45:656-665.

55. Sasaki K, Yamaguchi $H$, Aida R, Shikata M, Abe T, Ohtsubo N: Mutation in Torenia fournieri Lind. UFO homolog confers loss of TfLFY interaction and results in a petal to sepal transformation. Plant $J$ 2012, 71:1002-1014

56. Fukai E, Soyano T, Umehara Y, Nakayama S, Hirakawa H, Tabata S, Sato S, Hayashi M: Establishment of a Lotus japonicus gene tagging population using the exon-targeting endogenous retrotransposon LORE1. Plant J 2012, 69:720-730.

57. Miyao A, Tanaka K, Murata K, Sawaki H, Takeda S, Abe K, Shinozuka Y, Onosato K, Hirochika H: Target site specificity of the Tos 17 retrotransposon shows a preference for insertion within genes and against insertion in retrotransposon-rich regions of the genome. Plant Cell 2003, 15:1771-1780.

58. Miyao A, Iwasaki Y, Kitano H, Itoh J, Maekawa M, Murata K, Yatou O, Nagato $Y$, Hirochika $\mathrm{H}$ : A large-scale collection of phenotypic data describing an insertional mutant population to facilitate functional analysis of rice genes. Plant Mol Biol 2007, 63:625-635.

59. Kajiyama S, Inoue F, Yoshikawa Y, Shoji T, Fukusaki E, Kobayashi A: Novel plant transformation system by gene-coated gold particle introduction into specific cell using ArF excimer laser. Plant Biotechnol 2007, 24:315-320

60. Dudareva N, Pichersky E: Metabolic engineering of plant volatiles. Curr Opin Biotechnol 2008, 19:181-189

61. Mumm R, Posthumus MA, Dicke M: Significance of terpenoids in induced indirect plant defence against herbivorous arthropods. Plant Cell Environ 2008, 31:575-585.

62. Yu F, Utsumi R: Diversity, regulation, and genetic manipulation of plant mono- and sesquiterpenoid biosynthesis. Cell Mol Life Sci 2009, 66:3043-3052.

63. Arimura G, Matsui K, Takabayashi J: Chemical and molecular ecology of herbivore-induced plant volatiles: proximate factors and their ultimate functions. Plant Cell Physiol 2009, 50:911-923.

64. Arimura G, Shiojiri K, Karban R: Acquired immunity to herbivory and allelopathy caused by airborne plant emissions. Phytochemistry 2010, 71:1642-1649.

65. Maffei ME, Arimura Gl, Mithofer A: Natural elicitors, effectors and modulators of plant responses. Nat Prod Rep 2012, 29:1269-1368.

66. Dicke M, Baldwin IT: The evolutionary context for herbivore-induced plant volatiles: beyond the 'cry for help'. Trends Plant Sci 2010, 15:167-175 
67. Muroi A, Matsui K, Shimoda T, Kihara H, Ozawa R, Ishihara A, Nishihara M, Arimura G: Acquired immunity of transgenic torenia plants overexpressing agmatine coumaroyltransferase to pathogens and herbivore pests. Sci Rep 2012. in press.

68. Lucas-Barbosa D, Van Loon JJ, Dicke M: The effects of herbivore-induced plant volatiles on interactions between plants and flower-visiting insects. Phytochemistry 2011, 72:1647-1654.

doi:10.1186/1746-4811-9-23

Cite this article as: Nishihara et al.: Frontiers of torenia research: innovative ornamental traits and study of ecological interaction networks through genetic engineering. Plant Methods 2013 9:23.

\section{Submit your next manuscript to BioMed Central and take full advantage of:}

- Convenient online submission

- Thorough peer review

- No space constraints or color figure charges

- Immediate publication on acceptance

- Inclusion in PubMed, CAS, Scopus and Google Scholar

- Research which is freely available for redistribution 